\title{
Short Term Results of Fixation of Unstable Thoracolumbar Fractures with and without Intermediate Screws: A Comparative Study \\ Tarek Farghaly ${ }^{1}$, Ahmed Moursi ${ }^{1}$, Ahmed Elattar ${ }^{1}$, Moustafa Elsayed ${ }^{* 2}$, Ahmed Abdellatif ${ }^{3}$ \\ ${ }^{1}$ Orthopaedic Department, Alrazi Orthopaedic Hospital - Kuwait, \\ ${ }^{2}$ Orthopaedic Department, Sohag University Hospital, Sohag, Egypt \\ ${ }^{3}$ Orthopaedic Department, Aswan University Hospital, Aswan, Egypt \\ *Corresponding author: Moustafa Elsayed, Mobile: +201003142740, Email: mostafa.ismael79@ yahoo.com
}

\begin{abstract}
Background: Posterior short-segment pedicle screw fixation is widely used for unstable thoracolumbar (TL) fractures. Adding a pedicle screw at the fractured vertebrae could significantly improve the stability and decrease the stress on fixation construct.

Objective: Compare the efficacy of short segment pedicle screw fixation with and without intermediate screw in correction of the vertebral body height, local kyphosis and maintenance of the correction in the treatment of unstable thoracolumbar spine fractures.

Patients and Methods: This study was a prospective cohort study. 40 patients with unstable thoracolumbar fracture were divided randomly into 2 groups according to the surgical method used. In group B, 20 patients underwent fixation via short-segment pedicle screw instrumentation (1 level above and 1 level below the fractured level). In group A, 20 patients received additional screws at the fractured vertebrae.

Results: Both groups had significant correction in Cobb angle, anterior body height and local kyphotic angle. However group A had significantly higher correction achieved in Cobb angle (10.35 \pm 6.02$)$, anterior body height $(1.15 \pm 0.50)$ and local kyphotic angle (13.30 \pm 7.54$)$ than group B $(3.45 \pm 3.94),(0.40 \pm 0.41)$ and $(5.05 \pm 4.36)$ respectively. Nevertheless, the differences in VAS score $(\mathrm{p}=0.759)$ and ODI $(\mathrm{p}=0.934)$ were not significant. Moreover, group A had a significantly lower loss of correction in Cobb angle $(\mathrm{p}=0.025)$ after twelve months of follow up.
\end{abstract}

Conclusion: The construct with intermediate screw was associated with not only better correction but also less correction loss after 12 months. However, this was not reflected on clinical outcome.

Keywords: Intermediate screw, Thoracolumbar fractures, Pedicle screw.

\section{INTRODUCTION}

Posterior short-segment pedicle screw fixation (one level above and one level below the fracture level) is most widely used for TL fractures around the world, which can provide immediate spinal stability, improved correction of kyphotic deformities, early painless mobilization, and indirect decompression of the spinal canal. However, some authors reported that short-segment pedicle screw was not adequate to achieve and maintain the reduction of TL fractures and was associated with an unacceptable failure rate ${ }^{(\mathbf{1 , 2})}$.

Since a study of pedicle screw fixation at fractured vertebrae was first reported in 1994, a series of biomechanical studies also showed that pedicle screw fixation combined with screws at the fractured vertebrae could significantly improve the spinal stability and decrease the stress of pedicle screws in the upper and lower normal vertebrae ${ }^{(3,4)}$.

The operative procedure had the same steps in conventional short fixation and intermediate method but in intermediate method the screws are also inserted into the pedicle of the fractured vertebrae. The rod is introduced to the screw heads from distal to proximal and the distal screw head is tightened first. The proximal and intermediate screw heads are kept loose. With the help of a rod holder and a distractor, the proximal screws are distracted along the rod. The locking heads of the proximal and intermediate screws are tightened to secure the distraction achieved. Reduction is checked under fluoroscopy.

Aim of the present study was to compare the efficacy of short segment pedicle screw fixation with and without intermediate screw in correction of the vertebral body height, local kyphosis and maintenance of the correction in the treatment of unstable thoracolumbar spine fractures.

\section{PATIENTS AND METHODS}

This was a prospective comparative study conducted on 40 patients presented by unstable fractures of the thoracolumbar spine, conducted at the Alrazi Orthopaedic Hospital - Kuwait.

Patients with active systemic infection, severe osteoporosis and bilateral pedicle fractures were excluded. Patients' demographics are represented in Table 1. 
Table (1): Patients' demographics.

\begin{tabular}{|c|c|c|c|c|}
\hline & \multicolumn{2}{|c|}{$\begin{array}{c}\text { Group A } \\
(\mathbf{n}=20)\end{array}$} & \multicolumn{2}{|c|}{$\begin{array}{c}\text { Group B } \\
(\mathbf{n}=\mathbf{2 0})\end{array}$} \\
\hline & No. & $\%$ & No. & $\%$ \\
\hline Sex & & & & \\
\hline Male & 15 & 75 & 15 & 75 \\
\hline Female & 5 & 25 & 5 & 5 \\
\hline Age $($ Mean \pm SD $)$ & \multicolumn{2}{|c|}{$\begin{array}{c}31.20 \pm 14.85 \\
\text { years }\end{array}$} & \multicolumn{2}{|c|}{$\begin{array}{c}37.10 \pm 9.72 \\
\text { years }\end{array}$} \\
\hline Mode of trauma & & & & \\
\hline Motorcar accident & 10 & 50 & 6 & 30 \\
\hline Falling from height & 5 & 25 & 11 & 55 \\
\hline Falling on ground & 1 & 5 & 2 & 10 \\
\hline Motorcycle accident & 4 & 20 & 1 & 5 \\
\hline Level of fracture & & & & \\
\hline $\mathrm{T} 11$ & 2 & 10 & 3 & 15 \\
\hline $\mathrm{T} 12$ & 2 & 10 & 3 & 15 \\
\hline L1 & 10 & 50 & 10 & 50 \\
\hline L2 & 5 & 25 & 2 & 10 \\
\hline L4 & 1 & 5 & 2 & 10 \\
\hline AO classification & & & & \\
\hline $\mathrm{A} 2$ & 3 & 15 & 1 & 5 \\
\hline A3 & 14 & 70 & 17 & 85 \\
\hline A4 & 3 & 15 & 2 & 10 \\
\hline $\begin{array}{l}\text { Frankle grading } \\
\text { E }\end{array}$ & 19 & 95 & 20 & 100 \\
\hline $\mathrm{C}$ & . & 5 & 0 & \\
\hline
\end{tabular}

Patients were divided randomly into 2 groups according to the surgical method used. Group B; 20 patients underwent fixation via short-segment pedicle screw instrumentation. Group A; 20 patients received additional screws at the fractured vertebrae.

\section{Ethical approval:}

A written consent was taken from all patients and the study was approved by the Ethical Committee Board of our institution (Alrazi Orthopaedic Hospital).

All Patients underwent preoperative evaluation as regard history taking, clinical, neurological examination and radiographic imaging including preoperative plain radiography, computed tomography for assessment of pedicle and magnetic resonance imaging for evaluation of ligamentous injury and in neurocompromised patient. Postoperative evaluation was done radiographically using plain radiography immediately postoperatively, computed tomography at 3 or 6 months postoperatively and Cobb's angle was evaluated. The neurological status was evaluated according to ASIA score and the Oswestry disability index (ODI) was collected at 1, 3, 6 and 12 months postoperatively for conus injury patient.

Surgery was performed by a single senior spine surgeon, and the same instrumentation was used in all cases. Laminectomy was performed in only one patient with conus medullaris injury (Case no.1 in group A). Fusion was performed in all patients by using demineralized bone matrix (DBM) after fusion bed preparation using a high-speed burr. Early postoperative ambulation was done within 24 to 48 hours.

\section{Statistical analysis}

Data was analyzed using IBM SPSS version 20.0. (Armonk, NY: IBM Corp). Qualitative data were described using number and percent. The Kolmogorov-Smirnov test was used to verify the normality of distribution. Quantitative data were represented using range (Minimum and maximum), mean, standard deviation and median. Significance of the obtained results was judged at the 5\% level. Chisquare test was used to compare categorical variables between different groups. Mann Whitney test was used to compare abnormally distributed quantitative variables between two studied groups.

\section{RESULTS}

The study included 40 patients, $10(25 \%)$ females and $30(75 \%)$ males, with age range (14 - 62 years). The mean age was not significantly different between the two groups $(p=0.147)$. There was no significant statistical difference between the two groups according to mode of trauma $(p=0.143)$, fracture level $(\mathrm{p}=0.415)$ and $\mathrm{AO}$ classification $(\mathrm{p}=0.569)$.

According to intraoperative parameters, there were significant statistical differences between the two groups regarding operative time $(\mathrm{p}=0.008)$ but not intraoperative blood loss $(\mathrm{p}=0.225)$. The mean intraoperative time for group A $(96.0 \pm 8.68)$ was significantly higher than group B $(88.55 \pm 7.74)$. While the mean blood loss was $336.3 \pm 39.63$ and $325.3 \pm$ 44.02 for group A and group B respectively which were almost the same.

We found significant statistical differences in the measurements of Cobb angles immediately postoperatively, after six months and after 12 months (3.0 \pm 2.87 and $5.22 \pm 3.06$ and $7.39 \pm 3.97$ for group A respectively) and $(7.38 \pm 5.23$ and $11.13 \pm 6.98$ and $12.88 \pm 7.27$ for group B respectively) $(\mathrm{p}<0.001)$, but not preoperatively as the preoperative mean Cobb angle was $17.67 \pm 7.06$ for group $A$ and $15.56 \pm 7.04$ for group $\mathrm{B}(\mathrm{p}=0.284)($ Fig 1, 2). 


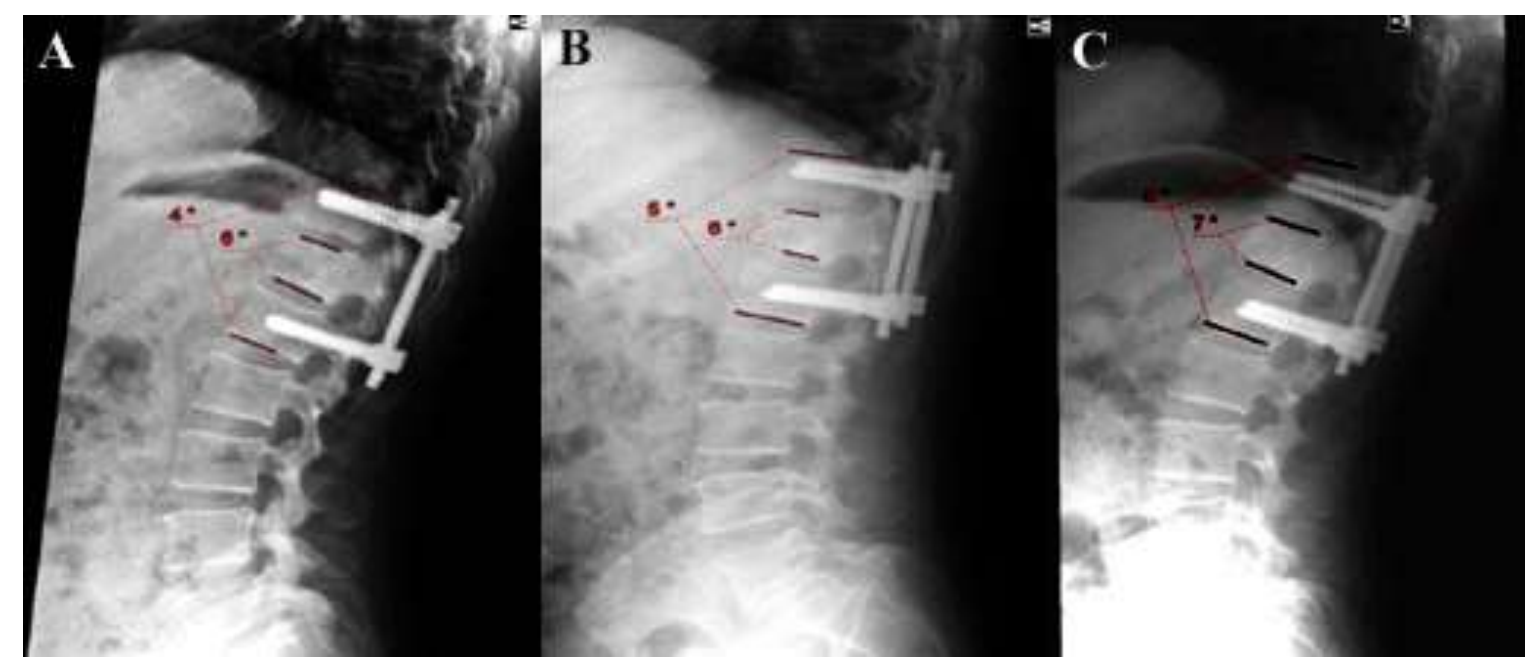

Fig. (1): Cobb angle and local kyphotic angle of group B; A. Immediate post X-ray, B. After 6 months, C. After 12 months.
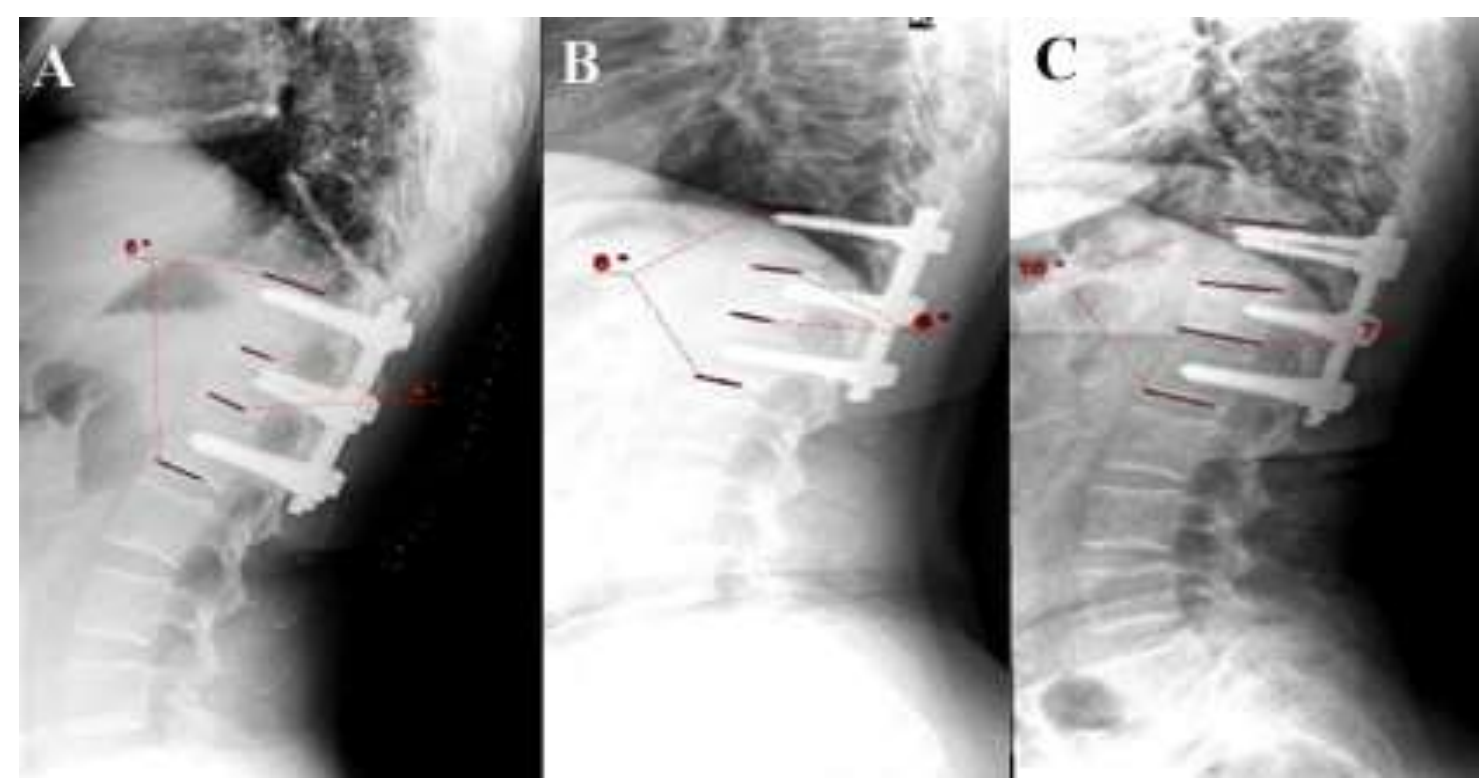

Fig. (2): A. Cobb angle and local kyphotic angle of group A; Immediate post X-ray, B. After 6 months, C. After 12 months.

There was a significant statistical differences between the two groups according to correction achieved in Cobb angle, in local kyphotic angle, which was $13.30 \pm 7.54$ and $5.05 \pm 4.36$ in group A and B respectively (Tables 2-3 and figures 3-4) and in anterior body height.

The mean anterior body height was $2.76 \pm 0.30,2.59 \pm 0.36$ and $2.53 \pm 0.36$ immediately postoperatively, 6 months and 12 months postoperatively respectively while for group B the mean height was $2.08 \pm 0.42,1.84 \pm 0.45$ and $1.76 \pm 0.46$ respectively.

Table (2): Comparison between the two studied groups according to correction achieved (Cobb angle).

\begin{tabular}{|c|c|c|c|c|}
\hline $\begin{array}{c}\text { Correction achieved } \\
\text { (Cobb Angle) }\end{array}$ & Group A $(\mathbf{n}=\mathbf{2 0})$ & Group A $(\mathbf{n}=\mathbf{2 0})$ & U & p \\
\hline $\begin{array}{c}\text { Preoperative } \\
\text { Min }- \text { Max }\end{array}$ & $5.0-31.0$ & $2.0-17.0$ & & \\
Mean \pm SD & $14.05 \pm 6.52$ & $8.45 \pm 3.95$ & $93.00^{*}$ & $0.004^{*}$ \\
Median & 13.50 & 8.0 & & \\
\hline After 12 months & $1.0-27.0$ & $-6.0-15.0$ & & \\
Min - Max & $10.35 \pm 6.02$ & $3.45 \pm 3.94$ & $60.50^{*}$ & $<0.001^{*}$ \\
Mean \pm SD & 10.0 & 3.50 & & \\
Median &
\end{tabular}

*: Statistically significant 


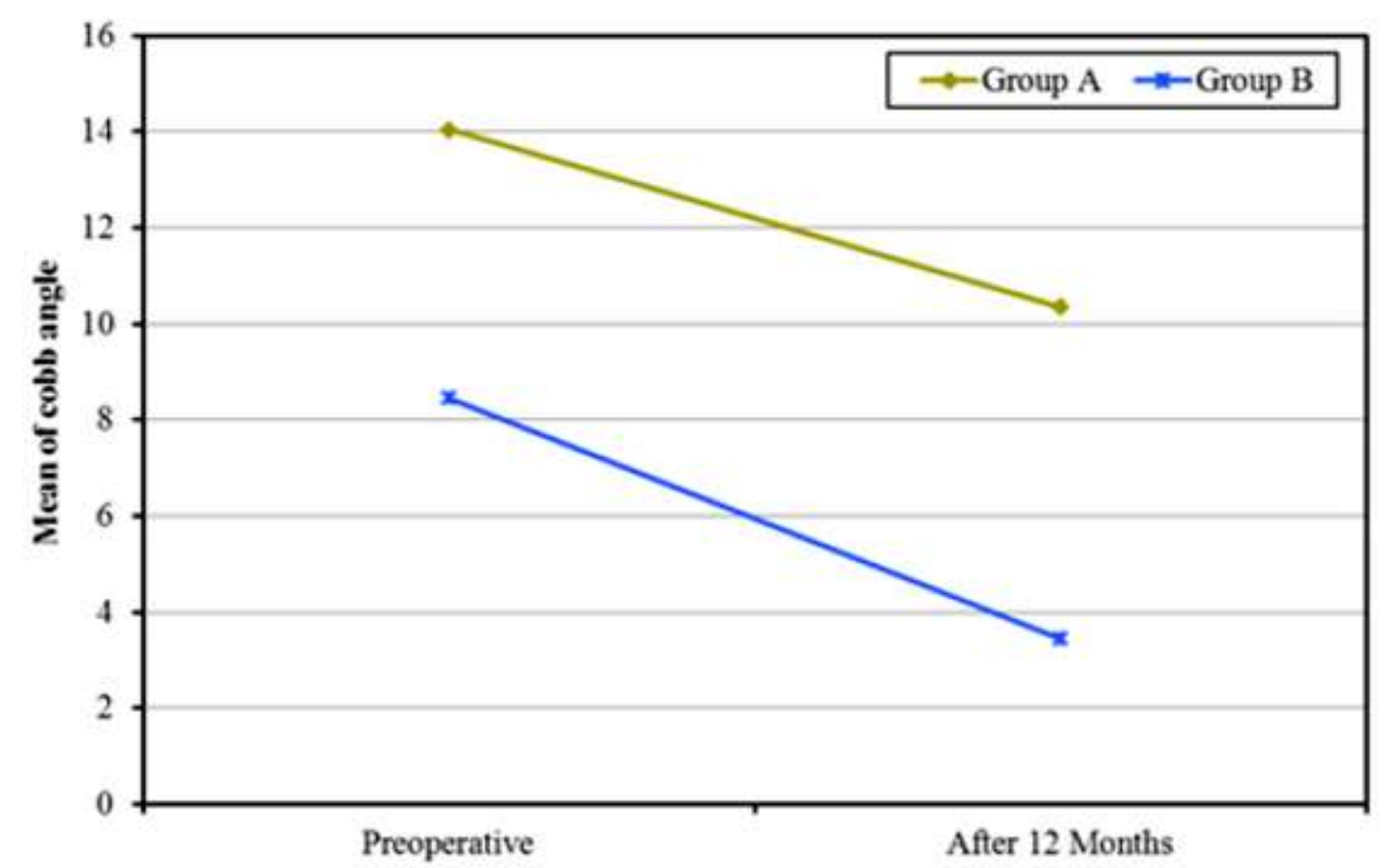

Fig. (3): Comparison between the two studied groups according to correction achieved (Cobb angle)

Table (3): Comparison between the two studied groups according to local kyphotic angle.

\begin{tabular}{|c|c|c|c|c|}
\hline Local kyphotic angle & Group A $(\mathbf{n}=\mathbf{2 0})$ & Group A $(\mathbf{n}=\mathbf{2 0})$ & $\mathbf{U}$ & p \\
\hline $\begin{array}{l}\text { Preoperative } \\
\text { Min }- \text { Max } \\
\text { Mean } \pm \text { SD } \\
\text { Median }\end{array}$ & $\begin{array}{c}6.0-33.0 \\
18.10 \pm 7.74 \\
13.50\end{array}$ & $\begin{array}{c}7.0-28.0 \\
15.30 \pm 6.26 \\
8.0\end{array}$ & 157.00 & 0.243 \\
\hline $\begin{array}{l}\text { Immediate postoperative } \\
\text { Min - Max } \\
\text { Mean } \pm \text { SD } \\
\text { Median }\end{array}$ & $\begin{array}{c}1.0-8.0 \\
2.70 \pm 1.75 \\
2.0\end{array}$ & $\begin{array}{c}2.0-18.0 \\
6.05 \pm 4.43 \\
5.00\end{array}$ & $80.00^{*}$ & $<0.001 *$ \\
\hline $\begin{array}{l}\text { After } 6 \text { months } \\
\text { Min }- \text { Max } \\
\text { Mean } \pm \text { SD } \\
\text { Median }\end{array}$ & $\begin{array}{c}2.0-9.0 \\
3.85 \pm 1.81 \\
3.0\end{array}$ & $\begin{array}{c}3.0-30.0 \\
8.45 \pm 6.46 \\
6.50\end{array}$ & $71.50^{*}$ & $<0.001 *$ \\
\hline $\begin{array}{l}\text { After } 12 \text { months } \\
\text { Min }- \text { Max } \\
\text { Mean } \pm \text { SD } \\
\text { Median } \\
\end{array}$ & $\begin{array}{c}2.0-13.0 \\
4.80 \pm 2.38 \\
4.0\end{array}$ & $\begin{array}{c}3.0-33.0 \\
10.25 \pm 6.89 \\
8.50 \\
\end{array}$ & $69.00^{*}$ & $<0.001 *$ \\
\hline
\end{tabular}

*: Statistically significant 


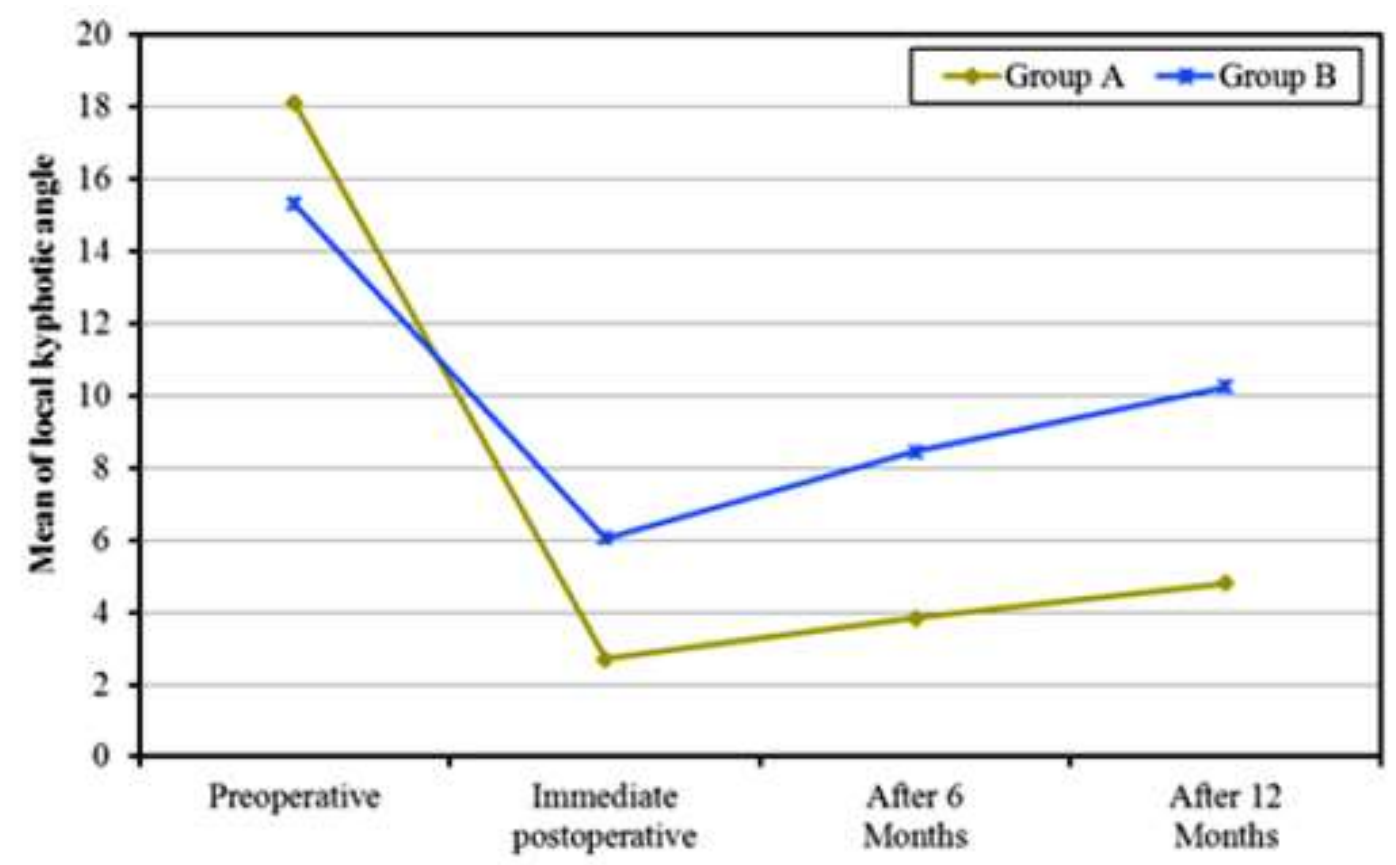

Fig. (4): Comparison between the two studied groups according to local kyphotic angle.

The differences between the two group according corrections in anterior body height after 12 months were also significant as the mean height was $1.15 \pm 0.50$ and $0.40 \pm 0.41$ for group A and group B respectively and $\mathrm{p}$ value was $<0.001$, correction achieved was significantly higher in group A than in group B. After 12 months the mean loss of correction was significantly lower in group A $(3.70 \pm 1.95)$ than in group $\mathrm{B}(5.55 \pm 3.05)(\mathrm{p}=0.025)$. There was only one case in our studied population (case number 33 Group B) was considered as a failure of fixation as 12 month-postoperative readings of cobb angle, anterior body height and local kyphotic angle deteriorated when compared to preoperative readings. As regards to clinical assessment, there were no significant statistical differences between the two studied groups neither for VAS score nor ODI score. These results were found not only preoperatively $(\mathrm{p}=0.417)$ and immediately postoperative $(\mathrm{p}=0.766)$, but also 6 $(\mathrm{p}=0.595)$ and 12 months $(\mathrm{p}=0.759)$ postoperatively.

\section{DISCUSSION}

Ye et al. ${ }^{(5)}$ totally agreed with our results as they found that overall correction of Cobb angel was significantly higher in the patients received intermediate screws 1 week after the surgery. They found also that the better correction in favor of intermediate screws was maintained in the follow up visits 6 and 12 months after the surgery.

A meta-analysis conducted ${ }^{(6)}$ in 2016 also matched our results regarding Cobb angle correction totally. The most recent meta-analysis of Tong et al. ${ }^{(7)}$ conducted in 2018, also was consistent with our findings as they showed that the combined intermediate screws fixation technique was associated with significantly improved radiologic outcomes. Although it was not a comparative study, Motizuki $\boldsymbol{e t}$ al. (8) also showed that the intermediate screws technique achieved a significant correction in Cobb angle and also had the ability to maintain that correction significantly till 12 months follow up period.

Zhao et al. ${ }^{(9)}$ found the posterior fixation including the fractured vertebra is obviously superior to traditional short segment fixation; however, it still cannot completely avoid fractured vertebra's shell-like change, the secondary losses in fractured vertebra's height and correction degree, or the failure of internal fixation. Present results found a significant higher restoration of the anterior body height with the intermediate screw technique. In addition to its ability to maintain a better result of correction as regards to Cobb angel and local kyphotic angel, this method was also able to maintain a better anterior body height at least for one year after surgery. This was in accordance to the recent study of Ökten et al. ${ }^{(10)}$; their comparative study included 70 patients who underwent short-segment stabilization because of the diagnosis of thoracolumbar (T11-L2) burst fracture between 2008 and 2012. They concluded that shortsegment instrumentation using additional screws at the fracture level in thoracolumbar burst fractures is a proper surgical approach for obtaining clinically and radiologically successful results in terms of the sagittal index, kyphosis angle, ratio of canal occupation, and correction of collapse in the anterior body. Two other studies ${ }^{(11,12)}$ have proved that.

Huang and Luo ${ }^{(13)}$ disagreed with our results as they found no significant statistical differences between short pedicle fixation with and without 
intermediate screws as regards to anterior body height, however, they reported a significant differences between the two groups in Cobb angle. Regarding loss of correction, we found significant differences between the two techniques according to Cobb angle as the mean loss of correction was significantly lower in the intermediate screw group. Huang and Luo ${ }^{(13)}$ showed the same as our observation in that the vertical stress screw fixation of fractured vertebrae is more effective at maintaining spinal postoperative physiological curvature of the spine and reducing the angle loss.

In contrast to our study Guven et al. ${ }^{(14)}$, remarked that there is no statistically significant difference between short segment fixation and short segment fixation plus intermediate screw regarding loss of correction. However, it was a retrospective radiographic review conducted to determine whether clinical factors or common classification systems can predict the radiologic outcome of short-segment thoracolumbar fracture fixation. Compared with conventional short pedicle technique, intermediate screw method can provide higher biomechanical stability. Firstly, a fractured screw-setting can exert a pressure stress toward the abdomen on the fractured vertebra, which can resist the suspension effect. Secondly, this procedure could improve the lateral stability of fixation. In addition, the additional fixation could reduce micro-movements on the bone-metal interface and provide higher screw pullout force ${ }^{(\mathbf{1 4})}$.

Our results showed significantly longer operative time with intermediate screw technique than the conventional method. The mean time was $96.0 \pm$ 8.68 and $88.55 \pm 7.74$ for intermediate and conventional time respectively. Zhao et al. ${ }^{\left({ }^{(9)}\right.}$ agreed to our results as they found that the mean time was 115 minutes for intermediate screws methods and 93 minutes for conventional method. Again, the most recent meta-analysis of Tong et al. (7) conducted in 2018, also matched our result as regard the operative time. However, some studies ${ }^{(14-16)}$ mismatched our results and found no significant differences between the two techniques as regards to operation time.

It is logical to find that intermediate screws technique having a longer operation time as it contains additional fixation point. However, operation time does not depend entirely on the used technique but also on surgeon talent and experience and intraoperative events and complications as well as patient's status at the time of operation. These facts may explain the heterogeneity in the results of operation time.

According to the current results the mean blood loss was $336.3 \pm 39.63 \mathrm{ml}$ for the intermediate method and $325.3 \pm 44.02 \mathrm{ml}$ for the other method, so there were no significant differences in blood loss between the two methods. Ye et $\boldsymbol{a l} .{ }^{(5)}$ found that the values of intraoperative blood loss were 507.5 \pm 300.0
$\mathrm{mL}$ and $483.5 \pm 186.6 \mathrm{~mL}$ for intermediate method and conventional method respectively, so they agreed with us in that there were no significant differences as regards to the amount of blood loss between the two groups.

From the 40 studied patients, only 7 patients had postoperative complications and these patients were distributed as follows: 1 patient had a seroma in group A, 2 patients had chest infection in group B and 2 patients had wound infection in each group. The distribution of these patients over the two groups shows that there were no significant statistical differences between the two groups as regards to postoperative complications. These results completely matched Dong et al. ${ }^{(17)}$ results as they found no significant differences between the two techniques as regards to rate of complications. They also reported the same types of complications. Many other studies $(\mathbf{8 , 9 )}$ agreed to our results according to the rate of complications but not the type of complications. Some found the most common complication was implant failure including breakage and loosening of the pedicle screws or the rods ${ }^{(11,12)}$ and others found that deep vein thrombosis was the most common complication ${ }^{(8,9)}$.

The mean hospital stay for our study population showed no significant statistical differences between the two techniques. To the best of our knowledge, no study disagreed with us in our finding as all previously mentioned studies matched our results except studies which did not record the hospital stay days in their results ${ }^{(5,18,19)}$.

\section{CONCLUSION}

The intermediate screw fixation technique was associated with better reduction of the fractured vertebrae, less correction loss in the follow-up and without additional complications. However, this was not reflected on clinical outcome as there was no significant statistical difference between the two groups. Given the lack of robust clinical evidence, these findings warrant verification in large prospective registries and randomized trials with long-term followup.

\section{REFERENCES}

1. Wood K, Bohn D, Mehbod A (2005): Anterior versus posterior treatment of stable thoracolumbar burst fractures without neurologic deficit: A prospective, randomized study. J Spinal Disord Tech., 18(1):S15-23.

2. McLain R, Sparling E, Benson D (1993): Early failure of short-segment pedicle instrumentation for thoracolumbar fractures. A preliminary report. J Bone Joint Surg Am., 75(2):162-7.

3. Baaj A, Reyes P, Yaqoobi A et al. (2011): Biomechanical advantage of the index-level pedicle screw in unstable thoracolumbar junction fractures. J Neurosurg Spine, 14(2):192-7. 
4. Bolesta M, Caron T, Chinthakunta S et al. (2012): Pedicle screw instrumentation of thoracolumbar burst fractures: Biomechanical evaluation of screw configuration with pedicle screws at the level of the fracture. Int J Spine Surg., 6:200-5.

5. Ye C, Luo Z, Yu X et al. (2017): Comparing the efficacy of short-segment pedicle screw instrumentation with and without intermediate screws for treating unstable thoracolumbar fractures. Medicine (Baltimore), 96(34):7893-96.

6. Li K, Zhang W, Liu D et al. (2016): Pedicle screw fixation combined with intermediate screw at the fracture level for treatment of thoracolumbar fractures: A metaanalysis. Medicine (Baltimore), 95(33): 4574-79.

7. Tong M, Tang Q, Wang C et al. (2018): Efficacy of using intermediate screws in short-segment fixation for thoracolumbar fractures: A meta-analysis of randomized controlled trials. World Neurosurg., 110: 271-80.

8. Motizuki H, Graells X, Zaninelli E et al. (2015): Treatment of thoracolumbar burst fractures fixed with intermediate pins by the posterior approach. Coluna/Columna, 14(3):223-6.

9. Zhao Q, Gu X, Yang H et al. (2015): Surgical outcome of posterior fixation, including fractured vertebra, for thoracolumbar fractures. Neurosciences, 20(4):362-66.

10. Ökten A, Gezercan Y, Özsoy K et al. (2015): Results of treatment of unstable thoracolumbar burst fractures using pedicle instrumentation with and without fracture-level screws. Acta Neurochir (Wien), 157(5):831-6.

11. Mahar A, Kim C, Wedemeyer M et al. (2007): Shortsegment fixation of lumbar burst fractures using pedicle fixation at the level of the fracture. Spine, 32(14):1503-7.
12. Defino H, Scarparo $P$ (2005): Fractures of thoracolumbar spine: Monosegmental fixation. Injury, 36(2): 90-7.

13.Huang W, Luo T (2013): Efficacy analysis of pedicle screw internal fixation of fractured vertebrae in the treatment of thoracolumbar fractures. Exp Ther Med., $5(3): 678-82$.

14. Guven O, Kocaoglu B, Bezer M et al. (2009): The use of screw at the fracture level in the treatment of thoracolumbar burst fractures. Journal of Spinal Disorders \& Amp Techniques, 22(6):417-21.

15. Farrokhi M, Razmkon A, Maghami $Z$ et al. (2010): Inclusion of the fracture level in short segment fixation of thoracolumbar fractures. Eur Spine J., 19(10):1651-6.

16. Yin F, Sun Z, Yin Q et al. (2014): A comparative study on treatment of thoracolumbar fracture with injured vertebra pedicle instrumentation and cross segment pedicle instrumentation. Zhongguo Xiu Fu Chong Jian Wai Ke Za Zhi., 28(2):227-32.

17. Dong J, Rong L, Liu B et al. (2009): Additional screws fixation on fractured vertebrae versus only short-segment posterior instrumentation for thoracolumbar a3 fracture without neurologic deficit. Zhonghua Wai Ke Za Zhi., 47(24):1883-7.

18. Naif A, Mohamed A, El-Sharkawi M et al. (2012): Intermediate pedicle screws for unstable thoracolumbar junction injuries. The Egyptian Orthopaedic Journal, 47(4):403-8.

19.Liao J, Chen W, Wang H (2017): Treatment of thoracolumbar burst fractures by short-segment pedicle screw fixation using a combination of two additional pedicle screws and vertebroplasty at the level of the fracture: A finite element analysis. BMC Musculoskelet Disord., 18(1):262-65. 